\title{
Managing Obesity and Glucose Intolerance with Bariatric Surgery, An Experience in Birdem General Hospital
}

\author{
FARUQ A $^{\mathrm{a}}$, HUSAIN MM ${ }^{\mathrm{b}}$, ZAFAR SMA $^{\mathrm{c}}$
}

\begin{abstract}
Background: Weight reduction is the cornerstone for managing obesity and Type 2 diabetes. Bariatric surgery, a concept used worldwide and recently introduced in Bangladesh is effective in achieving significant weight loss, improving and resolving comorbidities.
\end{abstract}

Materials and methods: This was a retrospective study thirty cases in whom bariatric surgery was carried out in the Department of Surgery in BIRDEM General Hospital were purposively sample for analysis.

Results: Thirty patients were operated of whom 3 were male and 27 female with the mean age of 40 years. Preoperative mean BMI was $47.1 \mathrm{~kg} / \mathrm{m}^{2}, 83 \%$ patients had diabetes, $60 \%$

\section{Introduction}

Obesity is increasing in incidence and it carries with it a significant health burden including the development of diabetes mellitus and its complications. The exponential increase in obesity has made it epidemic. ${ }^{1}$

Obesity is thought to be the primary cause of type 2 diabetes mellitus, and $90 \%$ of all diabetic patients are type 2 diabetes mellitus. ${ }^{2}$ It is estimated that individuals with $\mathrm{BMI}>40 \mathrm{~kg} / \mathrm{m}^{2}$ are 7 times more likely to develop diabetes mellitus than those with a BMI within a normal range. ${ }^{3}$ The association between obesity and type 2

a. Dr. Amreen Faruq, MS (Gen. Surgery) Registrar, Department of Surgery, BIRDEM General Hospital \& Ibrahim Medical College.

b. Dr. Muhd. Mustaque Husain, FCPS (Surgery) Assistant Professor, Department of Surgery, BIRDEM General Hospital \& Ibrahim Medical College.

c. Prof. S.M. Abu Zafar, FRCS, Professor, Department of Surgery, BIRDEM General Hospital \& Ibrahim Medical College.

Address of Correspondence: Dr. Amreen Faruq, Registrar, Department of Surgery, BIRDEM General Hospital \& Ibrahim Medical College, 122, Kazi Nazrul Islam Avenue, Shahbag, Dhaka-1000, Email: dramreen78@yahoo.com

Received: 05 November, 2013 Accepted: 10 February 2014 had hypertension. Twenty eight patients underwent laparoscopic sleeve gastrectomy, 1 gastric bypass and 1 open near-total gastrectomy with Roux-en-Y gastrojejunostomy. Postoperative mean BMI achieved was $34.4 \mathrm{~kg} / \mathrm{m}^{2}$. in the first year. Fifty two percent of the diabetic patients are now in good glycemic control with minimum drugs and $48 \%$ are in complete resolution.

Conclusion: Obesity and type 2 diabetes mellitus can be managed successfully with bariatric surgery.

Keywords: i) bariatric surgery,ii) laparoscopic sleeve gastrectomy, iii) obesity, iv) body mass index (BMI), v) type 2 diabetes mellitus.

(Birdem Med J 2014; 4(2): 70-73)

diabetes mellitus is so strong that the new term diabesity has now come into use in medical literature. ${ }^{4} \mathrm{~A}$ breakthrough in this association is really rewarding. Bariatric surgery at present is seen to be a highly effective surgical management in achieving and maintaining meaningful weight loss as well as treating obesity related comorbidities. It can cause clinical remission of diabetes in $64-83 \%$ of patients. ${ }^{5}$ Studies suggest that bariatric surgery can control diabetes and associated metabolic abnormalities by a mechanism independent of weight loss; as a result the use of bariatric surgery to cure type 2 diabetes mellitus is increasing even among less obese subjects.

In this study 30 patients were treated. Twenty eight patients underwent sleeve gastrectomy, a restrictive procedure and 1 gastric bypass and 1 near total gastrectomy.

Results are promising regarding excessive weight loss and diabetes control.

\section{Materials and methods}

This retrospective study was done in the Department of Surgery, BIRDEM General Hospital from December 2008 to June 2012 .Obese patients with a BMI $>40 \mathrm{~kg} / \mathrm{m}^{2}$ 
or BMI $>35 \mathrm{~kg} / \mathrm{m}^{2}$ with one or more comorbidities like diabetes mellitus, hypertension, osteoarthritis, sleep apnoea or patients of BMI $>30 \mathrm{~kg} / \mathrm{m}^{2}$ with diabetes mellitus not controlled with insulin and or antidiabetic drugs were included in this study. Non-compliant patients, super obese patients (BMI $>50 \mathrm{~kg} / \mathrm{m}^{2}$ ) due to inadequate facilities and obese patients with psychiatric illness were excluded from this study.

\section{Results:}

Total number of patients was 30 with female predominance $(27,90 \%)$. Mean age was 40 (17-55) years and mean BMI $47.1(31.1-59) \mathrm{kg} / \mathrm{m}^{2}$

Common comorbidities were diabetes mellitus $(25,83 \%)$ and hypertension $(18,60 \%)$. Other co morbidities are shown in the table-I.

Table-I

\section{Comorbidity of patients}

\begin{tabular}{lccc} 
Comorbidity & \multicolumn{3}{c}{ Patients } \\
& Male & Female & Total \\
\hline Diabetes mellitus & 1 & 24 & $25(83 \%)$ \\
Impaired glucose tolerance & 1 & 1 & $2(6.6 \%)$ \\
Hypertension & 2 & 16 & $18(60 \%)$ \\
Ischemic heart disease & 1 & 1 & $2(6.6 \%)$ \\
Osteoarthritis/knee joint pain & 3 & 17 & $20(66 \%)$ \\
Sleep apnea & 3 & 16 & $19(63 \%)$ \\
\hline
\end{tabular}

Regarding the treatment of diabetes mellitus 4 (16\%) were on oral anti diabetic drugs (OAD) and rest $21(84 \%)$ on Insulin + OAD. Twelve (48\%) required more than 100 units of Insulin. All diabetic patients had poor glycaemic control (Mean $\mathrm{HgA}_{1} \mathrm{C} 10 \%$ )

Most of the patients (28) underwent laparoscopic sleeve gastrectomy (LSG). Laparoscopic gastric bypass was done in one patient.

Open near total gastrectomy with Roux-en-Y gastrojejunostomy was done in a single patient as the patient had multiple gastric polyps (endoscopic finding).

Complications of the surgery are given below in the Table-III.
Table-II

\begin{tabular}{llc}
\multicolumn{2}{c}{ Complications } \\
Complication of bariatric surgery & $\begin{array}{c}\text { Number of } \\
\text { patients }\end{array}$ \\
\hline 1. & Per operative bleeding & 2 \\
2. Conversion from laparoscopic to & 1 \\
& open procedure & \\
3. Wound infection & 4 \\
4. Leak & 0 \\
5. Stricture & 0 \\
6. Death & 1 \\
\hline
\end{tabular}

Management of the preoperative bleeding was difficulty in the first two cases. Minor wound infection occurred in the four patients which was treated with regular dressing. One patient died on the seventh post operative day.

Twenty nine patients are on regular follow up after their surgery with a longest duration of 3 years in 6 patients. Mean postoperative BMI achieved in the first year was $34.4 \mathrm{~kg} / \mathrm{m}^{2}$ and mean excess weight loss was $43.1 \%$ and those achieved in the subsequent years are given in the table III. Maximum weight loss was found in the first year in all patients. Two patients were seen to gain weight two years after surgery although they had satisfactory weight loss in the first two years.

Table-III

\section{Follow up of patients}

Follow up No. of Mean postoperative Mean excess

\begin{tabular}{lccc} 
(years) & patients & BMI $(\mathrm{kg} / \mathrm{m} 2)$ & weightloss $(\%)$ \\
\hline 1 & 15 & 34.4 & 43.1 \\
2 & 9 & 30.2 & 53.6 \\
3 & 6 & 32.2 & 69.2 \\
\hline
\end{tabular}

Among the 25 diabetic patients, good glycemic control $\left(\mathrm{HbA}_{1} \mathrm{C}<7 \%\right.$ ) with minimum dose of insulin was found in $13(52 \%)$ patients and complete resolution $\left(\mathrm{HbA}_{1} \mathrm{C}<\right.$ $6.5 \%$ without medication) in $12(48 \%)$ patients. Out of the 18 hypertensive patients, $11(61 \%)$ patients required lower doses of antihypertensive drugs for blood pressure control and complete resolution (normal blood pressure without antihypertensive drugs) of hypertension found in 7 (39\%) patients. Of the 20 
patients with knee joint pain, pain decreased in the 11 (55\%) subjects while sleep apnea was improved in 9 (45\%) out of 19 subjects (Fig.-1).

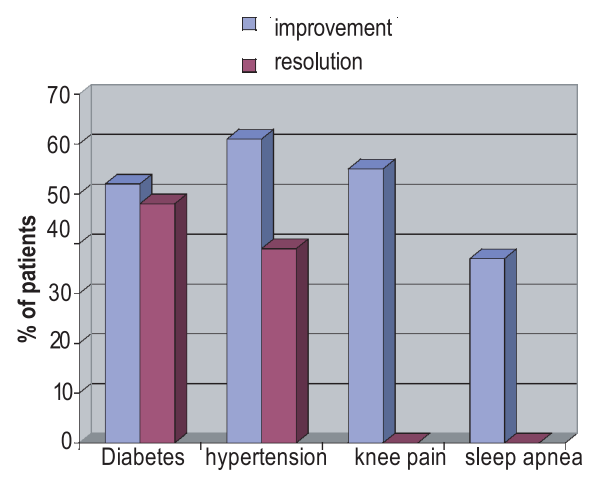

Fig.-1 : Follow u co-morbidities

\section{Discussion}

Bariatric surgery can prove to be one of the most important modalities for treating obesity and type 2 diabetes mellitus.

In our study the thirty patients who underwent bariatric surgery were initially seen and investigated by endocrinologists. All patients had been previously advised diet and exercise and those with diabetes or impaired glucose tolerance were given conventional medication. When satisfactory results were not achieved they were counseled for surgery. Twenty eight patients underwent laparoscopic sleeve gastrectomy (LSG). LSG (a restrictive bariatric procedure) was chosen for technical ease, there is no intestinal anastomosis required, there is normal intestinal absorption, no risk of hernia, no need for implantation of foreign body and since pylorus is preserved there is no dumping syndrome.

In two cases we faced difficulty with per operative bleeding. One case was converted into open procedure to control the per operative bleeding at the stapled line. After this, we started using reinforcement suture or glue at the stapled line. Although leak is the most concerning complication following sleeve gastrectomy, we have fortunately no leaks. In our series of 30 patients we have 1 death, which occurred at the initial stage the patient developed sudden, severe breathlessness, chest pain and cyanosis on the 7 th postoperative day. Death was possibly due to postoperative pulmonary embolism. Post mortem was not done (as patient party denied).
After surgery and subsequent follow ups our results show mean preoperative BMI was $47.1 \mathrm{~kg} / \mathrm{m} 2$ that decreased to mean postoperative BMI of $34.4 \mathrm{~kg} / \mathrm{m} 2$ and mean excess weight loss (EWL) of $43.1 \%$ in first year.

A systematic review of 36 studies recently evaluated overall weight loss after laparoscopic sleeve gastrectomy showed preoperative BMI of $51.2 \mathrm{~kg} / \mathrm{m} 2$ which reduced to $37.1 \mathrm{~kg} / \mathrm{m} 2$ showing the repeated follow up period predominantly 3 years.

The mean excess weight loss afteraparoscopic sleeve gastrectomy was reported in 24 studies $(n=1662)$ and ranged from $33-85 \%$ with an overall mean excess weight loss of $55.4 \%$. $^{6}$

Diabetes control and remission has been reported to different degrees after all recently performed bariatric procedures.In our patients significant reduction in insulin or oral hypoglycemic agents requirement was achieved within the first week at subsequent follow ups. Complete resolution in $40 \%$.

A recent systemic review by Gill and colleagues evaluated the rates of diabetes improvement after sleeve gastrectomy and found 28 studies that met their exclusion criteria. The patient population included 673 patients with a mean preoperative BMI of $47.4 \mathrm{~kg} / \mathrm{m} 2$. In this analysis laparoscopic sleeve gastrectomy resulted in diabetes remission in $66.2 \%$ of patients. Of those studies that reported improvement and remission of diabetes, $97 \%$ of patients had either improvement or remission. The mean HbA1C decreased from 7.9 to $6.2 .^{7}$ A study published by Dixon and colleagues demonstrates that patients undergoing bariatric surgery were more likely to obtain remission of diabetes mellitus than those treated with lifestyle modification. ${ }^{8}$ Several studies have compared laparoscopic sleeve gastrectomy and Rouxen-Y gastric bypass. In a prospective double blind study with 16 patients in each group, Karamanokas and colleagues reported weight loss, with laparoscopic sleeve gastrectomy in 1 year compared to Roux-en-Y gastric bypass. EWL $69.7 \%$ versus $60.5 \%$ respectively $(\mathrm{p}=0.5){ }^{9}$

Despite its wide acceptance, the long term durability of sleeve gastrectomy is still a concern.

Various studies were being carried out to find the factors which are responsible for durable weight loss such as the use of exact size of calibration tube and the critical 
size of the remaining stomach. Weiner and colleagues published the first 5 years weight loss in 2007 reporting their weight loss outcome related to calibration of the sleeve. ${ }^{10}$

Some patients are seen to regain weight long term after laparoscopic sleeve gastrectomy. These patients are good candidates for second stage procedure. ${ }^{7}$ Two of our patients who had lost satisfactory weight within the first two years after sleeve gastrectomy have regained some weight found on their last follow up and are under evaluation for further management.

\section{Conclusion}

Bariatric surgery is an effective modality of treatment of obesity and type-2 diabetes mellitus.

When conventional treatments fail patients with metabolic syndrome and comorbiditie associated with obesity can be considered for bariatric surgery. However, bariatric surgery is not the final answer unless patients are well counseled and willing to accept certain lifestyle modifications.

\section{References:}

1. Kelly T, Yang W, Chen CS. Global burden of obesity in 2005 and projections to 2030. Int J Obes (Lond) 2008;32:1431-37

2. CDC. National diabetes fact sheet: national estimates and general information on diabetes and prediabetes in the United States, 2011. Atlanta (GA): US Department of
Health and Human Services, Centers for Disease Control and Prevention; 2011.

3. Mokdad AH, Ford ES, Bowman BA. Prevalence of obesity, diabetes, and obesity-related health risk factors, 2001. JAMA 2003; 289:76-79.

4. Kothari SN, Epidemiology and economic impact of obesity and Type II diabetes, Surgical clinics of North America 2011; vol. 91: no. 6 .

5. Dixon JB. Obesity and diabetes: the impact of bariatric surgery on type-2 diabetes. World j Surg 2009; 33(10):2014-21.

6. Brethauer SA, Hammel JP, Schauer PR. Systemic review of sleeve gastrectomy as staging and primary bariatric procedure. Surg Obes Relat Dis 2009;5:469-75.

7. Gill RS, Birch DW, Shi X. Sleeve gastrectomy and type 2 diabetes mellitus: a systematic review. Surg Obes Relat Dis 2010; 6:707-13.

8. Dixon JB, O’Brien PE, Playfair J. Adjustable gastric banding and conventional therapy for type 2 diabetes: a randomized controlled trial. JAMA 2008; 299(3): 316-23.

9. Karamanakos SN, Vagena K, Kalfarentzos F. weight loss, appetite suppression, and changes in fasting and postprandial ghrelin and pepetide-YY levels after Rouxen-Y gastric bypass and sleeve gastrectomy: a prospective, double blind study. Ann Surg 2008; 247:401-7.

10. Weiner RA, Weiner S, Pomhoff 1. Laparoscopic sleeve gastrectomy- influence of sleeve size and restricted gastric volume. Obes Surg 2007; 17:1297-305. 